\title{
Inventário do Patrimônio Ferroviário
}

Denise Fernandes Geribello

Mestre em História pela Universidade Estadual de Campinas (UNICAMP)

\section{Resumo}

Tendo em vista a importância do inventário para a preservação e gestão do patrimônio ferroviário, este artigo faz uma reflexão sobre o ato de inventariar e apresenta o inventário integrante da pesquisa de mestrado Habitar o Patrimônio Cultural: o caso do ramal ferroviário Anhumas - Jaguariúna, desenvolvida no Departamento de História da Universidade Estadual de Campinas. A pesquisa tem como objeto de estudo o trecho da antiga Companhia Mogiana de Estradas de Ferro entre as Estações Anhumas e Jaguariúna, localizado nos municípios de Campinas e Jaguariúna, Estado de São Paulo. O seguinte texto aborda tanto questões gerais a respeito do inventário do patrimônio cultural quanto especificidades do patrimônio material ferroviário.

Palavras-chave: Patrimônio Industrial, Patrimônio Ferroviário, Inventário, Companhia Mogiana de Estradas de Ferro.

\begin{abstract}
Considering the important hole of the inventories on the preservation and management of the railway heritage, this article reflects on inventory and presents the inventory made by the master research "Inhabiting the Cultural Heritage: the study case of Anhumas - Jaguariúna railroad", developed in the History Department of Universidade Estadual de Campinas. This research has a section of the old railroad Companhia Mogiana de Estradas de Ferro as study case. This railroad is located in the cities of Campinas and Jaguariúna, São Paulo State. General issues on cultural heritage inventory and specificities of material railroad heritage are both broach in this article.
\end{abstract}

Keywords: Industrial Heritage, Railroad Heritage, Inventories, Companhia Mogiana de Estradas de Ferro.

Nas ultimas décadas, é crescente a produção de inventários do patrimônio cultural. Tais levantamentos são elaborados por entidades de caráter diverso e encerram finalidades e objetos de estudos distintos. A maior parte dos 
inventários é produzida por organizações governamentais e instituições acadêmicas, havendo, em alguns casos, parcerias entre estes dois tipos de entidade. Os bens imateriais e materiais, tanto móveis quanto imóveis, são tratados pelos inventários, que em alguns casos os tomam com objetos isolados e, em outros, como conjuntos. A seleção dos objetos inventariados é estabelecida a partir de recortes temáticos e ou espaciais. Os levantamentos destes bens têm por objetivo a identificação de elementos de interesse cultural, o aprofundamento do conhecimento a seu respeito ou mesmo a fundamentação de políticas públicas e intervenções. De acordo com o objeto de estudo e a finalidade, variam o caráter das informações e o grau de detalhamento dos levantamentos. Tendo em vista a crescente produção e diversidade dos inventários do patrimônio cultural, uma reflexão a cerca destes levantamentos constituiu o ponto de partida para a elaboração do inventário que integra a pesquisa de mestrado "Habitar o Patrimônio Cultural: o caso do ramal férreo Anhumas - Jaguariúna"1. As discussões que embasaram a criação deste inventário, bem como seu desenvolvimento e resultados, são abordados pelo presente texto.

Importante mencionar que o inventário é tratado pelo presente artigo como ferramenta de caráter investigativo e não como instrumento jurídico de proteção do patrimônio cultural. Esta abordagem se deve às demandas da pesquisa a qual o inventário se vincula, o que não quer dizer que a discussão sobre o inventário enquanto instrumento de proteção seja menos importante e necessária.

A pesquisa "Habitar o Patrimônio Cultural: o caso do ramal férreo Anhumas - Jaguariúna" tem por objetivo aprofundar o conhecimento sobre as relações funcionais e simbólicas entre bens culturais e seus habitantes. $O$ trabalho desenvolve o estudo de caso do trecho da linha tronco da antiga Companhia Mogiana de Estradas de Ferro $^{2}$ entre os pátios de Anhumas e Jaguariúna. Este trecho se estende pelos Municípios de Campinas e Jaguariúna,

\footnotetext{
${ }^{1}$ Pesquisa desenvolvida no Departamento de História do Instituto de Filosofia e Ciências Humanas da Universidade Estadual de Campinas, sob orientação da Professora Doutora Silvana Barbosa Rubino, com apoio da Fundação de Amparo à Pesquisa do Estado de São Paulo.

2 Inicialmente, esta companhia se intitula Companhia Mogyana de Estradas de Ferro. Em 1888, com o início das atividades de navegação no Rio Grande, ela passa a se chamar Companhia Mogyana de Estradas de Ferro e Navegação. Posteriormente, em 1923, com a desativação do serviço de navegação, volta a ser intitulada Companhia Mogyana de Estradas de Ferro, nome que passa a ser grafado com "i" em 1937. Neste texto, esta ferrovia será tratada como Companhia Mogiana.
} 
localizados na Região Metropolitana de Campinas, Estado de São Paulo. Fundamentado no inventário do complexo ferroviário e no levantamento das formas de apropriação material e simbólica deste complexo por seus habitantes, o estudo busca identificar implicações das diferentes formas de apropriação do patrimônio cultural por seus habitantes na sua preservação.

O complexo ferroviário estudado é constituído por um ramal férreo que ultrapassa 23 quilômetros de comprimento e conta com mais de 30 edificações de tipologias diversas distribuídas em seis pátios. Apesar de possuir algumas edificações remanescentes do traçado inicial da Companhia Mogiana, inaugurado em três de maio de 1875 (MATOS, 1981, p.71), o trecho estudado é resultante da retificação da ferrovia, que se estendeu de 1919 a $1945^{3}$ no segmento analisado. Este trecho foi desativado em 1977 (RIBEIRO, 2007, p. 14), após a encampação da Companhia Mogiana pelo governo estadual em $1952^{4}$, e sua integração à Ferrovia Paulista S/A em 1971 (RIBEIRO, 2007, p. 14). Em 1977, o trecho foi cedido em comodato à Associação Brasileira de Preservação Ferroviária $^{5}$ (ABPF) (RIBEIRO, 2007, p. 14), que implantou o trem turístico intitulado Museu Ferroviário Dinâmico Viação Férrea Campinas Jaguariúna no local em 1984․ Mesmo com a sua incorporação à Rede Ferroviária Federal e, posteriormente, a transferência à União, o trecho continua sob posse da ABPF, que ainda opera no local o trem turístico.

\footnotetext{
${ }^{3}$ RELATÓRIOS da Directoria da Companhia Mogiana de Estradas de Ferro para a Assemblea Geral de 1920 a 1945.

${ }^{4}$ BOLETIM da União dos Ferroviários Aposentados da Mogiana, Dez., 1992, p.4.

5 A Associação Brasileira de Preservação Ferroviária (ABPF) foi fundada em 1977 e reúne interessados na preservação e divulgação da história ferroviária no Brasil. A entidade teve como modelo associações existentes na Europa e nos Estados Unidos da América.

${ }^{6}$ ABPF Boletim, Dez., 2003, n. 10, p.4.
} 


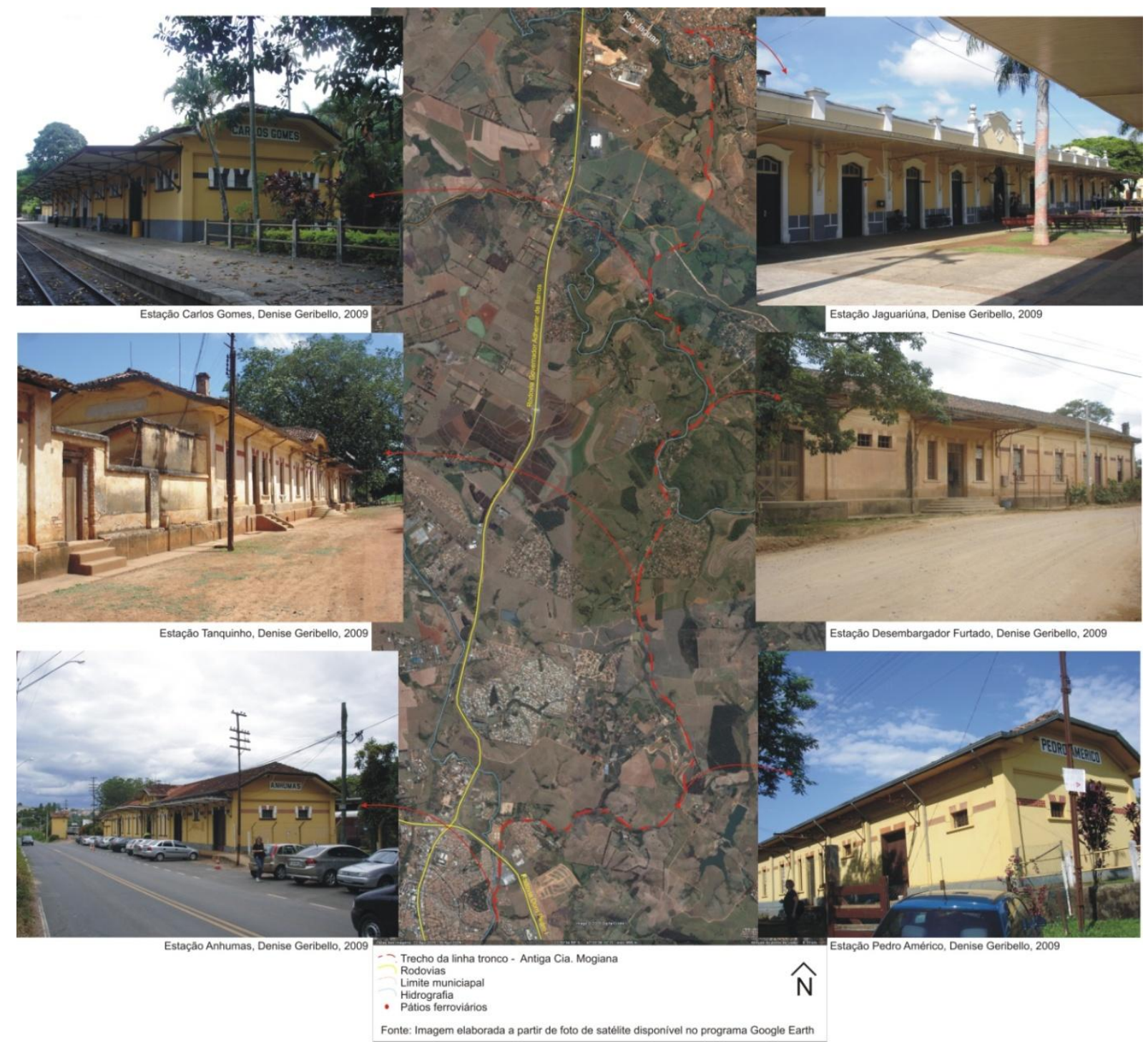

Figura 1. Pátios ferroviários do conjunto estudado

Além do patrimônio imóvel, constituído por edifícios, obras-de-arte e infraestrutura, o conjunto conta com grande acervo de bens móveis, composto por maquinário e material rodante, e com habitantes e freqüentadores que conservam técnicas e saberes associados às atividades ferroviárias. Pelo fato da análise da arquitetura e de suas formas de apropriação constituir o foco da pesquisa, apenas edifícios foram incorporados ao estudo. Por constituir um universo bastante amplo, foram abordados apenas os edifícios dotados de forma e dimensão que possibilitam a utilização como espaço de permanência. Dessa forma, edificações de pequena monta como casas de força e pequenos depósitos não foram incorporados ao trabalho. Este recorte se deve aos limites de tempo e ao tema da pesquisa, o que de modo algum significa que os elementos deixados de fora possuam menor relevância. Muito pelo contrário. 
Importante mencionar que, apesar do objeto de estudo se inserir em uma categoria bastante específica - patrimônio industrial ferroviário - a pesquisa busca abordá-lo sem perder de vista as questões mais abrangentes a cerca do patrimônio cultural e das disciplinas arquitetura e urbanismo. Conforme menciona Kühl, é necessário

"...tentar estabelecer linhas temáticas que permitam indagações que, por um lado, aprofundem aspectos específicos da discussão (arquitetura ferroviária, por exemplo) e, por outro, sejam articuladas com debates abrangentes em campos como a história, sociologia, antropologia e restauro que possibilitem uma compreensão mais ampla dos vários aspectos vinculados ao legado da industrialização" (2009, p. 46).

Assim sendo, as análises que fundamentam a elaboração do levantamento partem de uma abordagem das características gerais do inventário do patrimônio cultural e, em um segundo momento, tratam das especificidades do patrimônio ferroviário.

A seleção dos edifícios constituiu o ponto de partida para a elaboração do inventário. Tendo como recorte temático os edifícios do conjunto ferroviário da antiga Companhia Mogiana com forma e dimensão que possibilite sua utilização enquanto espaço de permanência e como recorte espacial o trecho entre as estações Anhumas e Jaguariúna, foram listados os bens a serem inventariados. Resultou desta atividade uma lista contendo vinte e nove edificações de tipologias diversas, entre elas estações, habitações e caixas d'água (Tabela 1). A definição dos bens a serem levantados se mostrou fundamental, mas não suficiente, para embasar a elaboração do inventário. Antes de definir sua forma e conteúdo, ainda se fizeram necessárias reflexões acerca do ato de inventariar e análises de inventários produzidos por entidades diversas. 
Tabela 1. Listagem das edificações inventariadas por pátio ferroviário

\begin{tabular}{|c|c|c|c|c|c|}
\hline Pátio Anhumas & $\begin{array}{l}\text { Pátio Pedro } \\
\text { Américo }\end{array}$ & $\begin{array}{c}\text { Pátio } \\
\text { Tanquinho }\end{array}$ & $\begin{array}{c}\text { Pátio } \\
\text { Desembargador } \\
\text { Furtado }\end{array}$ & $\begin{array}{l}\text { Pátio Carlos } \\
\text { Gomes }\end{array}$ & $\begin{array}{c}\text { Pátio } \\
\text { Jaguariúna }\end{array}$ \\
\hline Estação & Estação & Estação & Estação & Estação & Estação \\
\hline $\begin{array}{c}\text { Casa de } \\
\text { Portadores } 1\end{array}$ & $\begin{array}{l}\text { Casa de } \\
\text { Portadores }\end{array}$ & $\begin{array}{c}\text { Casa de } \\
\text { Portadores } 1\end{array}$ & $\begin{array}{c}\text { Casa de } \\
\text { Portadores } 1\end{array}$ & $\begin{array}{c}\text { Casa de } \\
\text { Portadores } 1\end{array}$ & Caixa d'água \\
\hline $\begin{array}{c}\text { Casa de } \\
\text { Portadores } 2\end{array}$ & $\begin{array}{c}\text { Casa de } \\
\text { Telegrafista } 1\end{array}$ & $\begin{array}{c}\text { Casa de } \\
\text { Portadores } 2\end{array}$ & $\begin{array}{c}\text { Casa de } \\
\text { Portadores } 2\end{array}$ & $\begin{array}{c}\text { Casa de } \\
\text { Portadores } 2\end{array}$ & Armazém \\
\hline $\begin{array}{l}\text { Casa de } \\
\text { bombeiro }\end{array}$ & $\begin{array}{c}\text { Casa de } \\
\text { Telegrafista } 2\end{array}$ & $\begin{array}{l}\text { Casa do } \\
\text { pessoal da } \\
\text { lavagem }\end{array}$ & $\begin{array}{c}\text { Casa de Turma } \\
1\end{array}$ & & \\
\hline \multirow[t]{3}{*}{ Caixa d'água } & $\begin{array}{c}\text { Casa de Turma } \\
1\end{array}$ & Caixa d'água & $\begin{array}{c}\text { Casa de Turma } \\
2\end{array}$ & & \\
\hline & $\begin{array}{c}\text { Casa de Turma } \\
2\end{array}$ & & Casa de Feitor & & \\
\hline & Casa de Feitor & & & & \\
\hline
\end{tabular}

O inventário consiste no registro, descrição e classificação de bens selecionados. Esta ferramenta articula de maneira sistematizada informações previamente existentes sobre o objeto a dados gerados pelo inventariante. Sua estrutura sistemática, além de orientar o olhar durante os levantamentos em campo e arquivo, também baliza o desenvolvimento de material gráfico, fotográfico e textual, permitindo, desta forma, certa padronização no levantamento. Tal configuração permite o cotejo de dados de forma objetiva, possibilitando tanto as análises propostas por seu autor quanto as apreciações de outros pesquisadores com os mais diversos enfoques, entre eles possíveis intervenções que venham ocorrer no objeto. Também decorre do caráter sistemático do inventário a possibilidade de abastecimento contínuo de dados.

À primeira vista, o inventário pode parecer um arrolamento imparcial de dados de cunho estritamente técnico, porém o caráter das informações nele apresentadas está ligado ao ponto de vista do inventariante, seja ele um individuo ou uma entidade. São as questões tidas como relevantes por seu autor que compõem o levantamento. Estas questões são organizadas segundo prioridades por ele impostas. As ferramentas de pesquisa, como, por exemplo, equipamentos de dimensionamento e análises laboratoriais, são selecionadas e utilizadas de acordo com critérios por ele colocados. Assim, a forma e o conteúdo do inventário, além de se relacionarem às peculiaridades do objeto e à finalidade do levantamento, se relacionam à perspectiva de seu autor, que, por sua vez, 
decorre de diversos fatores, como sua formação, experiência e contexto. Portanto, pode-se dizer que o inventário é temporal e culturalmente inserido.

A respeito da descrição de pinturas, Baxandall afirma que ela é "menos uma representação do quadro, ou mesmo uma representação do que se vê no quadro, do que uma representação do que pensamos ter visto nele" (2006, p. 44). De maneira análoga, pode-se dizer que o inventário, mais do que representar um objeto, representa o que é considerado relevante a respeito dele. O inventário não almeja, então, substituir o contato com o objeto ou o objeto em si, mas apresentar um ponto de vista sobre ele. Logo, além de informar a respeito da trajetória de um dado objeto e de sua situação em determinada época, o inventário também expõe a perspectiva pela qual tal objeto é considerado e quais informações a seu respeito são tidas como relevantes em um determinado período.

O inventário, com seu caráter sistemático, constitui uma importante ferramenta para dar conta de demandas do momento de sua elaboração. Com o passar de anos, meses e, em alguns casos, até mesmo dias após sua conclusão, os objetos inventariados sofrem modificações. Dessa forma, o inventário adquire valor documental, revelando informações sobre as formas e usos pretéritos de um bem. Como mencionado acima, o inventário pode revelar, ainda, a perspectiva a partir da qual os objetos são investigados em determinada época e local.

Antes de desenvolver o inventário proposto pela presente pesquisa e, assim, determinar a forma de tratamento do objeto, foi realizada uma análise de inventários existentes. Primeiramente foi desenvolvido um levantamento de inventários produzidos por diversas entidades, do qual dez inventários foram selecionados para compor uma apreciação mais específica. Estes dez inventários, indicados na Tabela 2, tiveram sua estrutura e conteúdo analisados com vistas a fundamentar a elaboração do inventário proposto pela presente pesquisa. 
Tabela 2. Inventários analisados

\begin{tabular}{|c|c|c|c|}
\hline Inventário & Instituição & Local & Ano \\
\hline Inventário do patrimônio imóvel de Açores & Instituto Açoriano de Cultura & Açores & 2008 \\
\hline Inventário de proteção do acervo cultural & $\begin{array}{l}\text { Secretaria de Indústria } \\
\text { Comércio e Turismo da Bahia }\end{array}$ & Salvador/BA & 1984 \\
\hline Inventário do patrimônio ferroviário & $\begin{array}{l}\text { Instituto do Patrimônio } \\
\text { Histórico e Artístico Nacional }\end{array}$ & Brasília/DF & 2007 \\
\hline $\begin{array}{c}\text { Arrolamento de conhecimento e varredura do } \\
\text { patrimônio ferroviário da extinta Rede Ferroviária } \\
\text { Federal }\end{array}$ & $\begin{array}{l}\text { Coordenação Técnica } \\
\text { Patrimônio Ferroviário/IPHAN }\end{array}$ & Brasília/DF & 2009 \\
\hline $\begin{array}{l}\text { Ficha de inventário dos bens imóveis tombados } \\
\text { pelo Município de Campinas }\end{array}$ & $\begin{array}{l}\text { Coordenaria Setorial do } \\
\text { Patrimônio Cultural da } \\
\text { Prefeitura Municipal de } \\
\text { Campinas }\end{array}$ & Campinas/SP & 2003 \\
\hline Percorsi di Catalogazione e Documentazione & $\begin{array}{c}\text { Centrale per Catalogo e La } \\
\text { Documentazione do Ministero } \\
\text { per i Beni e Le Attività Culturali }\end{array}$ & Italia & \\
\hline $\begin{array}{c}\text { Inventário de proteção ao acervo cultural de Minas } \\
\text { Gerais (IPAC/MG) }\end{array}$ & $\begin{array}{l}\text { Secretaria de Estado de } \\
\text { Cultura de Minas Gerais }\end{array}$ & Minas Gerais & 2008 \\
\hline $\begin{array}{l}\text { Inventário das vilas operárias de Campinas (1930- } \\
\text { 1960) }\end{array}$ & $\begin{array}{l}\text { Coordenaria Setorial do } \\
\text { Patrimônio Cultural da } \\
\text { Prefeitura Municipal de } \\
\text { Campinas/ Universidade } \\
\text { Estadual de Campinas }\end{array}$ & Campinas/SP & 2009 \\
\hline Projeto inventário de bens culturais imóveis & $\begin{array}{l}\text { Instituto Estadual do } \\
\text { Patrimônio Cultural do Rio de } \\
\text { Janeiro }\end{array}$ & $\begin{array}{l}\text { Rio de } \\
\text { Janeiro/RJ }\end{array}$ & 2004 \\
\hline Inventário da Região Central de Campinas & $\begin{array}{l}\text { Coordenaria Setorial do } \\
\text { Patrimônio Cultural da } \\
\text { Prefeitura Municipal de } \\
\text { Campinas/ Universidade } \\
\text { Estadual de Campinas }\end{array}$ & Campinas/SP & 2007 \\
\hline
\end{tabular}

A análise apontou a existência de pontos comuns aos inventários pesquisados. Dados referentes à localização, à propriedade, ao uso, ao estado de conservação e preservação, ao histórico do edifício, à proteção legal e à caracterização arquitetônica, construtiva e estilística integram todos os levantamentos. Apesar de aparecerem de maneira mais ou menos detalhada e, às vezes, com diferentes denominações, estes dados estão presentes em todos estes inventários.

Em uma parcela dos levantamentos, os edifícios são abordados como elementos isolados, tanto no espaço quanto no tempo. Em grande parte dos inventários, as formas de inserção territorial são pouco desenvolvidas, não evidenciando as relações do imóvel nem com seu entorno imediato nem com o tecido da cidade. Além de impedir sua leitura na trama urbana, tal forma de olhar o bem dificulta sua percepção enquanto elemento integrante de conjuntos arquitetônicos ou urbanísticos. A respeito do recorte temporal, a maioria dos inventários tem como foco a época de construção do edifício e o momento de elaboração do levantamento, de forma que a percepção do processo de evolução 
do objeto é comprometida. A restrição dos levantamentos ao contexto de formação do edifício e a sua situação atual pode estar ligada à busca da sociedade por suas origens e à tentativa de as conectar de alguma forma com o tempo presente, esforçando-se, dessa forma, no sentido de criação de um vínculo com o passado.

Outra questão pouco desenvolvida pelos inventários é a infra-estrutura existente nos edifícios. A presença ou ausência de pavimentação, abastecimento de água, gás encanado, rede de esgoto e de energia elétrica, telefone, internet... pode demonstrar o grau de representatividade de determinada região ou edifício frente à municipalidade, a qualidade de vida e as demandas de seus habitantes ou usuários, bem como o estágio de consolidação de uma região. Assim sendo, a inserção de informações relativas à infra-estrutura se faz necessária para uma melhor leitura do objeto e de seu contexto.

A falta de especificação das fontes de informações chama atenção em grande parte dos levantamentos analisados. Freqüentemente as obras e arquivos consultados são mencionados apenas na parte final da ficha, sem vinculação das informações às suas respectivas fontes. Dessa forma, a citação de dados contidos no levantamento ou mesmo sua verificação é comprometida.

Além de apresentar semelhanças em seus conteúdos, a estrutura dos inventários analisados também se aproxima. Os levantamentos, em sua maioria, são apresentados sob forma de tabelas, cujos campos se agrupam por categorias, contendo espaços para textos e imagens. Na maior parte dos casos, os espaços para imagens, geralmente fotografias, plantas e mapas, são escassos e demasiado pequenos. A impossibilidade de análise do objeto, ou de detalhes dele, e de seu entorno através das imagens as transforma em mera ilustração.

Por se tratar de uma pesquisa sobre o patrimônio industrial ferroviário, o inventário proposto, além de contar com as informações pertinentes ao objeto arquitetônico, deve dar conta das especificidades desta categoria. Elementos como a relação do edifício com o pátio ferroviário e a linha, a presença de maquinário ou material rodante, não são contemplados, a não ser por inventários específicos. As sistemáticas de inventário elaboradas pelo Instituto do Patrimônio Histórico e Artístico Nacional (IPHAN) para o levantamento do Patrimônio Ferroviário serviram como base para o entendimento destas demandas específicas. Trata-se do "Inventário do patrimônio ferroviário" e do "Arrolamento de varredura e conhecimento: patrimônio ferroviário - extinta 
RFFSA", ambos elaborados pela Coordenação Técnica do Patrimônio Ferroviário do Departamento de Patrimônio Material e Fiscalização para embasar as ações relacionadas à atribuição colocada ao IPHAN pela Lei $11.483 / 2007$ de

\footnotetext{
"receber e administrar os bens móveis e imóveis de valor artístico, histórico e cultural, oriundos da extinta RFFSA, bem como zelar pela sua guarda e manutenção" 7
}

Os principais aspectos específicos ao patrimônio ferroviário presentes nestes levantamentos são a inserção do objeto na linha férrea e a presença elementos integrados ao conjunto. A fim de situar o objeto na trama ferroviária, é proposta a identificação dos ramais e sub-ramais existentes, assim como da seqüência das edificações. Além de mapeada, a linha também é caracterizada quanto a suas operações - ativa, desativada ou erradicada. Quanto aos elementos integrados ao conjunto, é proposta a identificação de mobiliário, equipamentos de escritório, maquinário, ferramentas e acervo documental.

Tendo em vista as peculiaridades do objeto de estudo, assim como as reflexões e análises de inventários, foi desenvolvido um sistema de levantamento que visa, primeiramente, identificar o universo em que o objeto se insere e, posteriormente, aprofundar os conhecimentos a respeito edifício. Para tanto foram elaborados dois tipos de fichas, intituladas ficha do conjunto e ficha do edifício, que comportam níveis diferenciados de informações encerrando objetos, objetivos e abrangências específicas.

A ficha do conjunto tem como objeto cada um dos pátios ferroviários estudados. Nesta escala de abordagem o pátio é tratado enquanto conjunto e são analisadas tanto as relações entre os elementos que o compõe, quanto as relações entre o pátio, enquanto unidade, e o território. Além do estudo destas relações, integram a ficha informações a respeito de sua localização, tanto em relação à cidade quanto à linha, caracterização, propriedade, histórico, assim como da legislação incidente no conjunto.

Cada uma das edificações selecionadas é levantada através de uma ficha do edifício. Esta abordagem específica do imóvel tem como objetivo identificar suas características arquitetônicas e construtivas, além de traçar seus processos de transformação em diversas esferas, como modificações em sua materialidade,

${ }^{7}$ Lei $11.483 / 2007$ de 31 de maio de 2007 . 
propriedade e em suas formas de uso. O levantamento destas transformações permite a análise de implicação de modificação de um aspecto nos demais. Informações a respeito de sua localização, tanto em relação à cidade quanto à linha, caracterização, estado de preservação e conservação, infra-estrutura, assim como da legislação incidente, constam na ficha do edifício.

Ambas as fichas possuem um cabeçalho comum, que facilita a identificação das relações de pertencimento entre edifícios e conjuntos. As categorias e campos presentes na ficha do conjunto e do edifício estão listados na Tabela 3. Os tópicos indicados nesta tabela correspondem às informações textuais. Além destes campos, as fichas contam com espaços para inserção de imagens, constituídas, majoritariamente, por fotografias, mapas e croquis. Importante notar que as informações incorporadas ao inventário são acompanhadas de suas respectivas referências entre parênteses e ao final da ficha se situa a bibliografia.

Apesar do primeiro contato com as edificações, conferido pela listagem das edificações selecionadas, e da análise de inventários, foram necessárias revisões nas fichas após o início dos levantamentos. Tais modificações se devem a questões não previstas na elaboração inicial, que surgiram ao longo dos levantamentos de campo.

Tabela 3. Fichas de inventário

\begin{tabular}{|c|c|c|}
\hline & Categorias & Campos \\
\hline \multirow{14}{*}{ 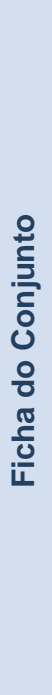 } & Identificação do estudo & $\begin{array}{l}\text { Recorte territorial, Recorte temático, Objeto de análise, Palavras } \\
\text { chave }\end{array}$ \\
\hline & Localização & $\begin{array}{l}\text { Município/UF, Sub-Prefeitura, Localidade, Código Postal, Endereço, } \\
\text { Contexto }\end{array}$ \\
\hline & Georreferenciamento & Latitude, Longitude, Altitude \\
\hline & Relação com a rede ferroviária & Linha, Km da linha, Operação \\
\hline & Objeto de análise & Natureza do bem, Categoria, Bens do conjunto \\
\hline & Propriedade & Propriedade, Posse, Contato \\
\hline & Período de construção & Ano, década, século, Observações \\
\hline & Histórico & Histórico do conjunto \\
\hline & Situação & Inserção territorial, Implantação \\
\hline & $\begin{array}{l}\text { Legislação incidente - Instrumentos } \\
\text { urbanísticos }\end{array}$ & Instrumento urbanístico, Lei, Data, Observações \\
\hline & $\begin{array}{l}\text { Legislação incidente - Proteção do } \\
\text { Patrimônio }\end{array}$ & $\begin{array}{l}\text { Esfera, Tipo, Data de abertura do processo, Data da resolução, Grau } \\
\text { de proteção, observações }\end{array}$ \\
\hline & $\begin{array}{l}\text { Fontes e documentação de } \\
\text { referência }\end{array}$ & Bibliografia, Arquivos pesquisados, Fortuna crítica \\
\hline & Anexos & Elaborações gráficas, Fotografias, Documentos variados \\
\hline & Preenchimento & Preenchido por, Data, observações \\
\hline
\end{tabular}




\begin{tabular}{|c|c|c|}
\hline & Categorias & Campos \\
\hline \multirow{20}{*}{ 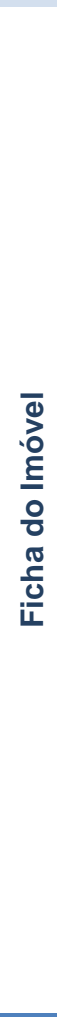 } & Identificação do estudo & $\begin{array}{l}\text { Recorte territorial, Recorte temático, Objeto de análise, Palavras } \\
\text { chave }\end{array}$ \\
\hline & Localização & $\begin{array}{l}\text { Município/UF, Sub-Prefeitura, Localidade, Código Postal, Endereço, } \\
\text { Contexto }\end{array}$ \\
\hline & Georreferenciamento & Latitude, Longitude, Altitude \\
\hline & Relação com a rede ferroviária & Linha, Km da linha, Operação \\
\hline & Objeto de análise & $\begin{array}{l}\text { Natureza do bem, Categoria, Tipologia, Denominação, Bens } \\
\text { Integrados }\end{array}$ \\
\hline & Propriedade & Propriedade, Posse, Contato \\
\hline & Período de construção & Ano, década, século, Observações \\
\hline & Autoria & Intervenção, Autor, Titulação, Data \\
\hline & Histórico & Histórico do edifício \\
\hline & Cronologia dos usos & Uso, Período, Observações (Campo passível de repetição) \\
\hline & Cronologia de propriedade & Proprietário, Período, Observações (Campo passível de repetição) \\
\hline & Caracterização arquitetônica & $\begin{array}{l}\text { Área edificada, Número de pavimentos, Configuração espacial, } \\
\text { Técnica construtiva, Características formais, Demais componentes } \\
\text { da edificação }\end{array}$ \\
\hline & Infra-estrutura & Infra-estrutura \\
\hline & Estado de conservação & Síntese do estado de conservação, Observações \\
\hline & Grau de alteração & Síntese do grau de alteração, Observações \\
\hline & $\begin{array}{l}\text { Legislação incidente - Instrumentos } \\
\text { urbanísticos }\end{array}$ & Instrumento urbanístico, Lei, Data, Observações \\
\hline & $\begin{array}{l}\text { Legislação incidente - Proteção do } \\
\text { Patrimônio }\end{array}$ & $\begin{array}{l}\text { Esfera, Tipo, Data de abertura do processo, Data da resolução, Grau } \\
\text { de proteção, observações }\end{array}$ \\
\hline & $\begin{array}{l}\text { Fontes e documentação de } \\
\text { referência }\end{array}$ & Bibliografia, Arquivos pesquisados, Fortuna crítica \\
\hline & Anexos & Elaborações gráficas, Fotografias, Documentos variados \\
\hline & Preenchimento & Preenchido por, Data, observações \\
\hline
\end{tabular}

Após a definição das fichas, o inventário foi preenchido a partir de levantamentos métricos, gráficos e fotográficos em campo. Os únicos equipamentos utilizados nos levantamentos de campo foram câmera fotográfica e trena laser, não foram feitas prospecções e as analises foram feitas a olho nu. Também foram pesquisadas fontes primárias, compostas, principalmente, por relatórios elaborados pela Companhia Mogiana e escassos croquis e plantas do complexo ferroviário, e secundárias, integradas por publicações e trabalhos acadêmicos que tratam da área de estudo, além de dicionários de arquitetura e construção.

Por se tratar de um primeiro levantamento do complexo ferroviário em questão, este inventário não tem caráter definitivo nem total. A proposta foi reunir a maior quantidade de informação possível em um determinado período de atividade, tanto para desenvolver a análise proposta pela pesquisa, quanto para gerar um banco de dados que possa ser complementado e utilizado em pesquisas futuras, com enfoques diversos. A fim de facilitar seu acesso e difusão, o inventário foi consolidado em meio digital.

O inventário resultou em seis fichas de pátios ferroviários e 29 fichas de edificações. Este material permite identificar pontos de aproximação e diferenças 
significativas existentes no próprio complexo ferroviário, embasando, desta forma a análise proposta pela pesquisa.

Longe de ditar uma forma mais correta ou eficiente para a elaboração de um inventário, este artigo buscou relatar uma experiência e levantar questões a respeito de elementos que foram considerados relevantes neste caso específico. Acredita-se que o essencial para um levantamento, independentemente de suas especificidades, seja a reflexão a respeito do conceito de inventário e dos inventários relativos ao tema estudado. Dessa forma, é possível intensificar o diálogo entre as informações de diferentes levantamentos de um mesmo tema ou objeto.

\section{BIBLIOGRAFIA}

ABPF Boletim, Dez., 2003, n. 10

BAXANDALL, Michael. Padrões de intenção: a explicação histórica dos quadros. São Paulo: Companhia das Letras, 2006.

BOLETIM da União dos Ferroviários Aposentados da Mogiana, Dez., 1992.

KÜHL, Beatriz M. Preservação do patrimônio arquitetônico da industrialização: problemas teóricos de restauro. Cotia: Ateliê Editorial, 2008.

MATOS, Odilon N. Café e Ferrovias: a evolução ferroviária de São Paulo e o desenvolvimento da cultura cafeeira. São Paulo: Arquivo do Estado, 1981.

RELATÓRIOS da Directoria da Companhia Mogiana de Estradas de Ferro para a Assemblea Geral de 1920 a 1945.

RIBEIRO, Suzana Barreto. Na linha da preservação: o leito férreo Campinas - Jaguariúna. Campinas: Direção Cultura, 2007. 